\title{
Dialogar com a dança
}

JOSÉ SASPORTES

Escritor e historiador de dança. Publicou em 1970 a primeira História da Dança em Portugal (Fundação Calouste Gulbenkian, Lisboa) e em 2011 coordenou a primeira Storia della danza italiana (EDT, Turim). Entre as duas datas, publicou e coordenou outros volumes sobre a história da dança, sendo de referir Pensar a Dança: A Reflexão Estética de Mallarmé e Cocteau (Imprensa Nacional-Casa da Moeda, Lisboa, 1983, 2006), traduzido para italiano em 1989 (Pensare la danza, Il Mulino, Bolonha, 1989). Em 1984 fundou a revista La Danza Italiana, dedicada à investigação da história da dança italiana. Como reconhecimento pelo seu trabalho neste domínio, a Associazione per la Ricerca in Danza Italiana homenageou-o em 2012 com o volume Passi, Tracce, Percorsi: scritti sulla danza italiana in omaggio a José Sasportes (Aracne, Roma). Nesse mesmo ano publicou A Quinta Musa: Imagens da história da dança (Bizâncio, Lisboa). Desde 2014 é vice-presidente do conselho de gestão da Carolyn Carlson Company, Paris. Em 2015 a Universidade Nova de Lisboa atribui-lhe o grau de doutor honoris causa.

The art of dance has been judged futile and dangerously sensuous. For those reasons it has been persecuted, but it also has had its advocates. First among them, Luciano, who wrote in Greek The Art of Dance, a dialogue between a supporter of dance and an enemy, who ends up converted to dance. In the Renaissance the text was translated into Latin, and since then it inspired further reflexions on the matter, also in dialogue form. Two topics from Luciano were repeated throughout the centuries: the dignity of dance and the opposition between dramatic dance and pure dance. This paper engages in the illustration of the permanence of arguments taken from Luciano until the twentieth century.

DANCE / PREJUDICE / HISTORY OF DANCE / PRECEPTS OF DANCE / DANCE CRITICISM

A forma de diálogo foi utilizada ao longo dos séculos, direi até milénios, para ilustrar o confronto entre os que dão diminuto valor à arte da dança e os que a enaltecem. Argumentos contrapostos que, no final dos diálogos, se traduzem na conversão à arte da dança dos que antes a menosprezavam. O uso do diálogo serviu ainda para traduzir visões antagónicas sobre a dança teatral, que uns desejavam mais abstrata e outros mais dramática.

O Diálogo sobre a Dança atribuído a Luciano é considerado o primeiro texto detalhado sobre a dança e a pantomima e veio a exercer, a partir do Renascimento, considerável influência nas reflexões sobre a dança, e até sobre as suas práticas. Teria sido redigido em grego (Pěri ŏrchēsěōs) por Luciano Samosatense, 
nascido cerca do ano 120 próximo do rio Eufrates, na província romana da Síria.

Nesse Diálogo, a personagem Licino começa por dizer:

Há muito que premeditaste este terrível ataque contra todos os tipos de dança, contra a própria arte coréutica, até contra nós, os que nos deleitamos com tal espectáculo, como se nos dedicássemos a uma coisa nula ou reservada às mulheres, a ti, Cratone, quero dizer quanto estás longe da verdade e como, sem te dares conta, tens vilipendiado um dos melhores prazeres desta vida. Desde sempre tens considerado a dança indigna, mas talvez tenhas desculpa considerando que levas uma vida esquálida, guiada apenas pela morigeração.

(Luciano, 1992: 51) 1

Ao longo dos séculos, mais do que qualquer outra arte, a dança tem sido denegrida como frívola e perigosamente corruptora dos bons costumes. Condenação presente desde o tempo dos Romanos, como se evidencia no Diálogo de Luciano, mas mais activamente exercida pelos censores católicos e protestantes, e ainda hoje, passadas as condenações moralistas, a arte da dança, apesar da sua popularidade, é vista com displicência, não só nos meios académicos. Para responder a esta postura, a argumentação de Licino, a personagem que Luciano contrapõe ao denegridor Cratone, pode esclarecer-nos.

Luciano cita os encómios feitos à dança por Homero, Hesíodo, Platão, Tucídides, Plutarco, lembra deuses e heróis que dançaram, descreve as proezas de bailarinos e de pantomimos, enaltece o carácter formativo da dança para quem a exercita e para quem a vê. Luciano dá muito mais espaço ao apologista do que ao acusador Cratone, senhor já avançado nos anos que nunca teria assistido a um espectáculo de pantomima, mas que no fim do diálogo acaba convencido pelas razões do amigo, percebe o que até então tinha perdido e pede-lhe para o levar ao teatro da próxima vez que lá se deslocar.

Uso aqui indiferentemente as palavras dança e pantomima, salientando, como referem os eruditos, que a palavra pantomima não existia no grego ático. Aliás, o próprio Luciano afirmava que eram os Romanos quem designava os bailarinos como pantomimos, por serem capazes de tudo imitar. 
Luciano defende que os temas que o pantomimo pode ilustrar são os mesmos da tragédia e que o bailarino, descrito como sapiente e ágil, tem de conhecer a fundo a história antiga, memorizando-a, sabendo representar os eventos mais famosos, «desde o caos primordial do nascimento do mundo até ao tempo de Cleópatra». E passa a fazer um minucioso elenco destes temas, que séculos mais tarde servirá de guia aos coreógrafos do ballet d'action ou bailado pantomimo. Para Luciano, «a componente principal da profissão de pantomimo é uma espécie de ciência mimética e demonstrativa que sabe exprimir os pensamentos e iluminar o que está na sombra».

Dois séculos depois de Luciano, um outro escritor oriundo da Síria, Libânio, propõe uma Oração em Defesa da Pantomima, da qual sobreviveram trinta códices. Foi já assinalado que a existência destas defesas supõe a existência de ataques, mas os textos respectivos não se conhecem. «É certamente um caso singular que, de entre todas as obras que se presumem compostas à volta da querelle sobre o valor da dança, os amanuenses medievais tenham feito chegar até nós apenas os textos favoráveis à pantomima, apesar de esta ter sido hostilizada continuamente pelos Padres da Igreja dos primeiros séculos» (Beota, 1992: 25).

No caso de Libânio, não se trata de um diálogo mas de uma resposta à distância de décadas a um outro autor, Públio Élio Aristides, que acusara a dança de imoralidade em texto que desconhecemos. É um diálogo à distância em que Aristides é directamente interpelado e que termina com a apologia da pantomima. Libânio descreve detalhadamente a dura preparação dos aspirantes a bailarinos, sendo particularmente severo no que respeita a dieta:

Tal como para quem tem a paixão de escrever, também para os alunos da pantomima a fadiga é o maior recurso para concretizar as suas aspirações. Assim como é impossível engordar o corpo e ao mesmo tempo refinar a alma, também não é possível que a glutonaria e a dança andem de braço dado, sendo essencial que quem deseja uma esteja longe da outra. [...] Sem autodisciplina é impossível aprender este mister.

(Savarese, 2003: § 106)

A igreja medieval censurou a dança em todas as suas formas, tomando-a como reminiscência do paganismo e recusando-lhe 
qualquer papel no culto. A partir do século XIV, porém, paralelamente com a constituição de pequenas e grandes cortes, a dança ganhou espaço na vida social e nas representações espectaculares, sendo significativo que, nas crónicas dos reis portugueses da segunda dinastia, sempre se destaquem as suas competências bailatórias. Nos séculos XV e XVI escrevem-se os primeiros tratados de dança, muito seguidos, a julgar pela quantidade dos manuscritos que chegaram até hoje. A sempre maior complexidade das festas e dos espectáculos apoia-se na cenografia e na coreografia, que vai requerer acrescida profissionalidade, além da disponibilidade e da competência dos cortesãos. Em finais do século XV, surgem em Itália e em França as primeiras traduções latinas de Luciano e o seu Diálogo sobre a Dança passa a constituir a base da erudição sobre esta arte, sendo arma de defesa e de ataque entre os amadores e os detractores da dança.

Em 1549, Zuccolo da Cologna publicou em Pádua um libelo frontal com um título bem explícito, La Pazzia del Ballo, «A Loucura da Dança», que assim começa: «Antes que a nossa loucura entre numa dança e mais debilite o pouco cérebro dos tolos e dos desvairados de que vos falarei, parece-me razoável demonstrar várias opiniões sobre as origens e a antiguidade da dança, e quanto era apreciada por vários povos gentios» (Zuccolo, 1969:3).

Sem o citar, Zuccolo serve-se de quanto dizia Luciano a favor da dança e como se abonava nos deuses que dançavam, para lhe inverter o sentido e dizer que só em âmbito pagão a dança podia ser louvada. Fala da corrupção dos costumes que a dança implica e considera-a uma antecâmara do adultério.

Tal libelo pedia uma resposta, que assume, como em Luciano, forma de diálogo entre duas posições opostas. Em 1555, Rinaldo Corso publica em Veneza o seu Dialogo del Ballo, que, sem nunca referir Zuccolo, bem se ilustra como uma contraposição às opiniões por ele defendidas. O Dialogo é entre uma dama de nome Frigia e um cavaleiro de nome Cirneo, ele a favor, ela contra: «não entendo como se possa defender a loucura da dança.» Cirneo vai desfolhando as razões avançadas por Luciano, que continua a não ser nomeado. A transposição do diálogo original catorze séculos depois teria assim clara justificação quando aplicada às danças cortesãs e aos espectáculos festivos, embora estes não tivessem alcançado ainda a qualidade dos antigos, segundo o próprio Cirneo, 
que é a voz do autor, Rinaldo Corso. A jovem vai argumentando em sentido contrário, mas também aqui se deixa convencer, declara que não mais falará da loucura da dança e acaba aceitando o convite para dançar de Cirneo, que em todo o diálogo aproveitara para a cortejar.

Apesar de em Portugal continuar a ser difícil ainda hoje aplicar genericamente os princípios da educação pela arte, e em particular pela dança, já há quase cinco séculos Rinaldo Corso a advogava no seu Dialogo:

\begin{abstract}
É útil exercitar a harmonia através da dança, em primeiro lugar por que as crianças são atraídas para a virtude de um modo agradável, depois por o exercício ser benéfico para a saúde do corpo enquanto a criança está a crescer e enche a barriga de comida pouco sã, e também por a dança formar e ajudar à boa disposição dos membros, a tudo acomodando uma pessoa.

(Corso, 1987: 40)
\end{abstract}

O opúsculo de Corso teve uma segunda edição em Bolonha em 1557, e em 1620 Filippo degli Alessandri da Nardi imprimiu em Terni um Discorso sopra il Ballo em que plagiou sem remorsos largas passagens de Luciano e de Corso, não indicando as fontes, o que atesta que a argumentação continuava a parecer válida.

Em 1599, o acrobata Archangelo Tuccaro publicou em Paris Trois dialogues de l'exércice de sauter et voltiger dedicados ao rei de Nápoles, em que reaparece Luciano e se discutem teses opostas sobre a dança. O interlocutor, de nome Cosme, «um grande e poderoso inimigo da dança», afirma: «Não basta não pecar, é preciso afastarmo-nos de tudo o que tem a aparência do pecado. A propósito da dança, seja qual for o seu pretexto, não está isenta de vício e o tempo que a ela se dedica é verdadeiramente tempo perdido» (Tuccaro, 1599: 16v).

Mais adiante, serve-se de um olhar extra-europeu para condenar danças que, a ser verídica a asserção, talvez sejam as que os missionários jesuítas portugueses encenavam para benefício dos povos a cristianizar:

Veja o que escreveu o douto Vines contando que no Extremo Oriente, nas terras recém-descobertas pelos portugueses, os nativos dessas regiões ao ver muitos homens bailar e dançar, girando e saltando, como se costuma por aí fazer, ficaram amedrontados e fugiram rapidamente de tal companhia, pois lhes parecia que estes homens se comportavam como 
pessoas endiabradas possuídas por um qualquer demónio que assim as teria furiosamente impressionado e agitado.

Luciano continuou a ser largamente utilizado em diversos quadros de história da dança em Itália, em França e em Inglaterra, e na segunda metade do século XVIII a sua influência foi decisiva para uma viragem na estética da dança, tendo sido a Encyclopédie o primeiro veículo para a difusão das novas ideias através da pena de Louis de Cahusac e de Diderot, que, aliás, igualmente se serviu do modelo retórico do diálogo entre facções opostas no celebrado Paradoxo do Actor. Desta vez não se tratou de ir buscar a ajuda de Luciano para contrariar os inimigos da dança, mas para reforçar novas propostas que levassem à passagem da dança simples à dança em acção, para usar as palavras do tempo. Por dança simples, entendiam-se os divertimentos das óperas, e por dança em acção o projecto de emular a pantomima antiga e fazer dançar as paixões dos deuses e dos homens como Luciano prescrevia. Louis de Cahusac, no volume La danse ancienne et moderne, de 1754, defende esta tese e cita, nomeando-o, o longo elenco feito por Luciano dos temas susceptíveis de serem tratados em dança. Fala também das proezas de dois mimos romanos do tempo de Augusto, Pílades e Batilde. Quanto ali escreveu foi em seguida retomado por Jean Georges Noverre nas celebradas Lettres sur la Danse, de 1760, e por Gaspare Angiolini, que, no prefácio ao programa do bailado Le Festin de Pierre dado em Viena em 1761 com música de Gluck, também recorre a Luciano, e segue o mesmo percurso na Dissertation sur les ballets pantomimes des anciens, impressa igualmente em Viena em 1767 quando da apresentação do bailado Semiramis, baseado na tragédia homónima de Voltaire, sempre com música de Gluck.

Noverre e Angiolini conseguirão impor no circuito europeu da ópera e da dança italianas o novo bailado pantomima, mas, trabalhando para os mesmos públicos, comportar-se-ão como rivais que reclamam a primazia da implantação da nova poética. Deste confronto não nascerão diálogos entre os opositores e os seus apoiantes, mas antes uma outra forma de argumentar com a publicação num mesmo opúsculo de cartas contrastantes. Numa fala um defensor de Noverre, noutra um defensor de Angiolini, assim nascendo um diálogo perante os olhos do leitor. A polémica 
entre os dois coreógrafos, a única que se conhece nestes termos, animou com muitas publicações o circuito dos teatros de Milão e de Viena, ambos então sob a tutela austríaca. ${ }^{2}$

Poucos anos depois, Milão foi cenário de uma outra polémica, desta vez em torno do chamado coreodrama de Salvatore Viganò, que exacerbava a vontade de a dança continuar a apropriar-se da temática trágica recomendada por Luciano. Viganò era figura de grande prestígio na cena europeia, e Stendhal comparou a sua obra à de Shakespeare. Por ocasião da estreia no Scala de Milão, em 1813, de uma nova versão de As Criaturas de Prometeu, dada inicialmente em Viena com música de Beethoven, desencadeou-se grande agitação no meio cultural milanês, seja pela temeridade do argumento, seja pelo desrespeito da lei das três unidades da tragédia clássica, e mais uma vez se discutia se era ou não lícito isentar a tragédia dançada deste espartilho. Escreveram-se artigos, fingiram-se correspondências pró e contra, como no caso da polémica Noverre-Angiolini. Ermes Visconti, personagem de primeiro plano da cena literária milanesa, concebeu um diálogo em que fez figurar personagens reais, como o próprio Viganò e o compositor Paisiello. A conclusão foi que as três unidades tinham perdido a razão de ser tanto para a dança como para o teatro: avançava-se o exemplo de Shakespeare e justificava-se Viganò (Tomassini, 1999: 148-176). Curiosamente, dez anos depois, Stendhal, milanês de adopção, plagiou este diálogo em Racine et Shakespeare, um quase manifesto do teatro romântico, para repudiar igualmente a regra aristotélica sobre a necessidade de o espectáculo teatral respeitar a unidade de acção, de tempo e de local.

No período romântico, que se divorciou do classicismo e da mitologia, Luciano foi sendo esquecido, embora M.A. Baron, em Lettres et entretiens sur la danse ancienne, moderne, religieuse, civile et théâtrale (Paris, 1824) o tenha seguido e tenha adoptado a forma de diálogo para discutir sobre dança com Sophie.

No início do século $\mathrm{xx}$, Luciano regressa por causa de Isadora Duncan e da sua ideia de reformar a dança a partir do exemplo grego, opondo-se à dança académica. Pierre Louÿs, o poeta e romancista amigo de André Gide, de Debussy e de Paul Valéry, autor de uma versão francesa do Diálogo das Meretrizes, de Luciano, publicou em 1910 um Dialogue sur la danse, em que 
transparece como modelo o diálogo de Luciano. Discutem uma bailarina anónima e um $\mathrm{Moi}$, um eu que é a voz do autor. Ela é favorável ao ballet e desdenha Isadora Duncan, que não saberia dançar; ele aceita a glória de uma estrela de escola italiana da Ópera de Paris, Rosita Mauri, mas diz-se seduzido pela arte de Isadora Duncan. Retoma-se uma dicotomia setecentista entre a dança que se basta a ela própria como pura dança - hoje o exemplo seria Balanchine - e a dança que encarna significados emotivos para além de formais.

Isadora dançou e Pierre Louÿs ficou deslumbrado:

Ela [surge], anima as antigas estatuetas gregas e as figuras dos vasos que víamos imóveis parecem ressuscitar; ou melhor ela inventa, reconstitui, que dizer? Interpreta, naturalmente. Os movimentos da cabeça tão antigos e tão novos que ora colocam o pescoço na linha do braço, ora na linha do corpo: é a ressurreição da dança ateniense.

(Louÿs, 1973: 12)

E que mais poderia desejar o autor das Chansons de Bilitis? Pierre Louÿs enaltece Isadora, mas é também capaz de apreciar a arte da sua interlocutora e a de Ida Rubinstein, que os Ballets Russes trouxeram a Paris, mas o diálogo conclui-se sem que a bailarina se mostre convencida, ao contrário do que sucedia nos diálogos anteriormente citados, em que uma parte reconhecia a razão da outra. Esta contraposição insolúvel é profética, pois define campos ainda hoje não conciliados, como veremos no fim desta intervenção.

Em plena efervescência dos Ballets Russes, Paul Valéry, que há algum tempo nada publicara, entrega à Revue Musicale o diálogo «L'Âme et la Danse». Estamos em 1921, mas Valéry situa o diálogo no final de um simpósio onde se exibem um grupo de bailarinas e a sua estrela Athiket. Platão discorre sobre a dança com Fedro e Erixímaco. $\mathrm{O}$ diálogo é uma extrema exaltação da dança, sem confronto nem vitória final. Valéry disse não ter querido fazer referências directas ao movimento coreográfico seu contemporâneo, embora a bailarina dance sobre as pontas e os seus movimentos pareçam evocar, contraditoriamente, os de Isadora Duncan. Para escrever este pastiche de um diálogo socrático, Valéry ter-se-ia baseado em reminiscências de vagas leituras gregas, mas a presença de Luciano, talvez por indicação de Pierre Louÿs, não é descartável, embora nunca tenha sido nomeado a 
propósito deste texto. Porém, a frase chave do diálogo, tantas vezes citada, «A bailarina é um puro acto de metamorfoses» (Valéry, 1921: 21), estava já em Luciano quando comparava um bailarino a Proteu por ser capaz, como aquela divindade, de mudar rapidamente de aspecto, de se metamorfosear. Imagem que as glosas de Luciano ao longo dos séculos não se cansaram de repetir. Noutra passagem sobre a relação entre os movimentos que se vêem e os sons que os acompanham, Valéry faz Sócrates observar: «[...] se a sigo com as orelhas tapadas, [a bailarina] é de tal modo ritmo e música que me é impossível não ouvir o som das cítaras» (idem, 10).

Luciano conta que o filósofo cínico Demétrio, reticente à arte da pantomima, depois de ver a demonstração de um pantomimo que se fizera entender sem a música e sem os coros, teria dito: «Não só vejo mas oiço quanto fazes e parece-me serem as tuas mãos a falar.»

Os três interlocutores de Valéry detêm-se bela e longamente sobre a fusão da alma e do corpo que se materializa através da dança, mas já Luciano notara que «alguns espectáculos são a expressão de uma ou de outra parte do homem, da mente ou do corpo, mas na dança as duas partes estão fundidas».

O mais singular, porém, é o recuo de Valéry ao tempo helénico quando os Ballets Russes dominavam a cena parisiense. A renovada vitalidade da dança dava que pensar, e o recuo no tempo poderia oferecer a distância conveniente para interpretar a sua dinâmica. Valéry retoma a questão do significado da dança já aflorada por Pierre Louÿs e faz a sua personagem Sócrates sintetizar as sensibilidades contrastantes dos seus dois interlocutores:

Sócrates - ... Oh! meus amigos eu continuo a perguntar-vos o que é a dança, ambos parecem sabê-lo, mas sabê-lo de maneira diferente. Um diz-me que ela é o que é e se resume ao que temos diante dos nossos olhos; outro defende com firmeza que ela representa algo, e que por isso o seu significado não está inteiramente nela mas sobretudo em nós. Quanto a mim, meus amigos, a minha incerteza está intacta! Os meus pensamentos são inúmeros - o que nunca é um bom sinal!... Inúmeros, confusos, e enleados à minha volta...

(idem, 21)

Sócrates concluirá que a dança é da natureza do fogo e que a bailarina é uma chama incontrolável nas suas vibrações. O problema do significado da dança e das formas de a abordar pelos artistas e pelo público mantém-se, contudo, intacto. 
É sempre necessário algum escrúpulo quando abordamos de um modo concreto um texto poético-filosófico como «L'Âme et la Danse», mas também é impossível não o referir à época em que foi escrito.

Se a correspondência é uma forma de diálogo, a resposta que em Julho de 1911 Stravinsky deu ao seu amigo Andrey Rimsky Korsakoff, filho do famoso compositor, vem inserir-se apropriadamente neste contexto. Stravinsky, fresco de ter visto dançar pelos Ballets Russes os seus Pássaro de Fogo e Petruchka, apresenta-se como um ardente defensor do Ballet:

E agora falemos apaixonadamente do que pões em causa, ou seja o Bailado. Embora digas não seres inimigo do Bailado, depois afirmas que é uma arte cénica menor. Com esta afirmação, tudo se me torna claro, pois queres dizer que o Bailado não te agrada e não Ihe atribuis uma qualquer importância. Devo corroborar que para mim é exactamente o contrário. Adoro o Bailado, que me interessa mais do qualquer outra coisa. Não se trata de um entusiasmo passageiro, mas de um prazer sério e profundo perante esta forma teatral, perante esta arte das formas animadas. Muito me surpreende verificar a pouca importância que atribuis à coreografia, tu que tanto amas as artes plásticas, que tanto te interessas pela pintura e pela escultura - a menos que agora também estas te deixem frio. Surpreende- me a tua falta de interesse por esta arte, considerando o Bailado inferior à Ópera. Ao admirar os frescos da Capela Sistina, sou levado a pensar que se Miguel Ângelo fosse vivo a única arte que reconheceria e aceitaria seria a arte coreográfica que agora renasce, e teria sem dúvida considerado miserando tudo quanto hoje se vê nos teatros.

(apud Taruskin, 1996: 972-873)

E Stravinsky insiste:

Penso que se tu assistisses regularmente aos espectáculos de Bailado (de Bailado artístico bem entendido), te terias apercebido como esta forma de «arte inferior», como tu dizes, te pode oferecer um prazer artístico incomparavelmente superior ao de qualquer ópera (incluindo as tuas óperas preferidas). Um prazer que me satisfaz há mais de um ano e que desejo partilhar contigo. É como o prazer de descobrir um novo continente. O seu desenvolvimento requer muito trabalho, mas tem ainda tanto para oferecer. (idem, ibidem)

Infelizmente Stravinsky não convenceu o amigo, e após a criação da Sagração da Primavera em 1913 esta amizade ficou irremediavelmente comprometida. 
A moda da utilização retórica dos diálogos para discorrer sobre a dança foi-se esbatendo, mas é curioso notar como certas questões levantadas ao longo dos séculos nos diálogos precedentes se reapresentam a cada nova viragem no curso da história da dança, e tal poderemos verificar agora através de um diálogo real ocorrido em 1985, e que Ann Daly reproduz em 2002. A coreógrafa Reinhild Hoffmann e Jochen Schmidt, crítico e biógrafo de Pina Bausch, discutem com críticos americanos após uma série de espectáculos de Pina na Brooklyn Academy de Nova Iorque. Nessa ocasião, a crítica americana manifesta não se ter convertido à nova dança alemã, referida como «European trash» (lixo europeu). O nó da dissidência era ainda e sempre o do significado da dança. Reinhild Hoffmann explicava que

em tudo há forma, em tudo há movimento. Umas vezes acentuamos mais um aspecto, outras vezes o outro. É uma simples questão de escolha. $\mathrm{Na}$ Europa talvez estejamos mais ligados à tradição teatral. Em todas as cidades existe um teatro de ópera com as obras tradicionais. Talvez por essa razão continuamos a querer contar histórias, a mostrar personagens, a dizer algo sobre o ser humano para além de propormos apenas forma ou movimento. (apud Daly, 2002)

Contrariando-a, Nancy Goldner, guardiã dos tesouros balanchinianos, afirmava que os conteúdos eram desnecessários:

De uma maneira geral, penso que a característica principal da dança americana é a de que os coreógrafos estão interessados em valores de movimento.

Cada gesto, cada passo, têm a sua legitimidade próprias, a sua beleza e a sua expressividade. Está tudo aqui e trata-se de saber usá-lo.

(idem, ibidem)

Os alemães defenderam-se como puderam dos ataques dos norte-americanos e nenhuma das partes convenceu a outra, o que bem nos diz ser mais fácil chegar a uma conclusão nos diálogos de ficção do que na vida real. Os termos da discussão não são hoje diferentes dos que afloraram no passado e cada nova criação coreográfica reabre o debate, felizmente. Observando os espectáculos que desfilam perante os nossos olhos, cabe-nos o encargo de contar e de interpretar a história destas flutuações. 


\section{REFERÊNCIAS BIBLIOGRÁFICAS}

BEOTA, Simone (1992), «Introduzione», in Luciano, La Danza, trad. Marina Nordera, Veneza, Marsilio, pp. 9-44.

Corso, Rinaldo (1987), Dialogo del ballo, Verona, Amis (inclui reprodução da edição de 1555).

DALY, Ann (2002), Critical Gestures: Writings on Dance and Culture, Middletown, Wesleyan University Press.

LOMBARDI, Carmela (ed.) (1998), Il Ballo Pantomimo: Lettere, saggi e libelli sulla danza (1773-1785), Turim, Paravia scriptorium.

LOUŸs, Pierre (1973), «Dialogue sur la danse», Euvres complètes, t. XI, Genebra, Slatkine Reprints. LUCiAnO (1992), La Danza, trad. Marina Nordera, Veneza, Marsilio.

SAVARESE, Nicola (2003), «L'orazione di Libanio in difesa dei pantomimi», in Teatro greco postclassico e teatro latino: teorie e prassi drammatica, Roma, Herder Editrice, pp. 435-455.

TARUSKIN, Richard (1996), Stravinsky and the Russian Traditions, vol. II, Berkeley University of California Press. tomassini, Stefano (ed.) (1999), Prometeo, libretto del ballo, con i testi della polemica, Turim, Legenda. TU C C ARO, Arcangelo (1599) Trois dialogues de l'exercice de suater et voltiger en l'air, Paris, Claude de Monstr'oeil.

VALÉry, Paul (1921) «L'Âme et la Danse», Revue Musicale, Paris, Nouvelle revue française. zU CC O Lo da Cologna (1999), La Pazzia del Ballo, Bolonha, Forni Editore. 